\title{
Analisis Efektivitas Mesin Produksi Menggunakan Pendekatan Failure and Mode Effect Analysis dan Logic Tree Analysis
}

\section{Production Machine Effectiveness Analysis Using Failure and Mode Effect Analysis and Logic Tree Analysis}

\author{
Dhita Febriyanti ${ }^{1}$, Erika Fatma ${ }^{2 *}$ \\ 1,2Program Studi Manajemen Logistik Industri Elektronika, Politeknik APP Jakarta, Jl. Timbul No.34, \\ Jagakarsa 12630, Jakarta Selatan, Indonesia
}

Diterima: 4 Januari 2018; Direvisi: 4 Februari 2018; Disetujui: 23 Februari 2018

\begin{abstract}
ABSTRAK
Penelitian ini menggunakan metode Overall Equipment Effectiveness (OEE) untuk mengukur efektivitas mesin blowing pada pabrik pembuatan botol plastik. Selain itu, metode ini digunakan untuk mengetahui faktor kerugian atau kerusakan yang memberikan dampak terbesar terhadap efektivitas mesin. Setelah nilai efektivitas mesin diketahui, selanjutnya dilakukan analisis Failure Mode and Effect Analysis (FMEA) dan Logic Tree Analysis (LTA). Kedua metode tersebut mengidentifikasi dan mencegah sebanyak mungkin faktor yang dapat menimbulkan kegagalan produksi. Berdasarkan hasil pengamatan, rendahnya nilai OEE dipengaruhi oleh performance efficiency. Kegagalan yang paling memengaruhi efektivitas mesin ditunjukan oleh faktor dengan nilai Risk Priority Number (RPN) diatas nilai kritis.
\end{abstract}

Kata Kunci: Overall Equipment Effectiveness, Failure Mode and Effect Analysis, Logic Tree analysis

\begin{abstract}
This research uses the Overall Equipment Effectiveness (OEE) method to measure the blowing machine effectiveness at the plastic bottle manufacturing plant. This paper investigates losses that gave the biggest impact on machine effectiveness value. Afterwards analytical methods are used in this paper, using Failure Mode and Effect Analysis (FMEA) and Logic Tree Analysis (LTA). Both methods identify as many causes as the failure that can decrease machine effectiveness. OEE value was influenced by low-performance efficiency. Failure that most affect the effectiveness of the machine is shown by factors with the value of Risk Priority Number (RPN) above the critical value.
\end{abstract}

Keywords: Overall Equipment Effectiveness, Failure Mode and Effect Analysis, Logic Tree analysis

\section{PENDAHULUAN}

Saat ini, sebagian besar perusahaan cenderung untuk mengalihdayakan sebagian proses produksinya kepada pihak lain. Bagi perusahaan yang melakukan produksi untuk perusahaan lain, ketepatan penyelesaian dan jaminan kualitas menjadi penting. Hal ini menuntut perusahaan untuk memastikan bahwa seluruh alat/mesin produksinya dapat berfungsi optimal tanpa gangguan, sehingga target jumlah produksi dan kualitas produk dapat memenuhi target.
Perusahaan yang diamati merupakan produsen kemasan minuman plastik. Proses produksi di pabrik ini hanya menggunakan satu jenis mesin, yaitu mesin molding tipe blowing. Permasalahan yang dihadapi oleh perusahaan adalah mesin sering mengalami kerusakan mendadak dan produk yang dihasilkan tidak memenuhi spesifikasi yang ditetapkan. Disisi lain perusahaan terikat kontrak dengan perusahaan lain, sehingga harus memastikan bahwa produk dihasilkan dengan kualitas dan waktu yang tepat.

*email: err.fatma@gmail.com 
Dalam hal ini, perusahaan seharusnya memiliki sistem untuk memonitor kinerja mesin produksi. Namun, perusahaan belum memiliki prosedur pengukuran efektivitas mesin. Efektivitas merupakan ukuran yang menyatakan seberapa jauh target (kuantitas, kualitas, waktu) telah tercapai. Penelitian ini dilakukan untuk mengukur efektivitas mesin yang dapat memberikan rekomendasi perencanaan pemeliharaan mesin produksi.

Pemeliharaan mesin adalah rangkaian aktivitas untuk mempertahankan kualitas mesin agar dapat berfungsi dengan baik (Ansori dan Mustajib, 2013). Salah satu metode yang digunakan untuk menghitung efektivitas mesin adalah OEE (Muchiri dan Pintelon, 2008). Perhitungan OEE dilakukan dengan membandingkan nilai ketersediaan mesin (availability), efisiensi kerja (performance effeciency), dan mutu produk (quality rate).

Selanjutnya, dilakukan analisis yang mempertimbangkan penyebab kegagalan yang bersumber dari berbagai komponen, dan analisis keandalan dengan menelusuri pengaruh kegagalan komponen yang dinilai kritis. Analisis yang digunakan adalah Failure Mode and Effect Analysis (FMEA) dan Logic Tree Analysis (LTA). Kemudian, menilai tindakan perbaikan yang diperlukan dan mereduksi faktor kegagalan kritis. Analisis ini melakukan perhitungan RPN untuk menentukan kegagalan tertinggi. Nilai RPN dihitung berdasarkan hubungan antar variabel yaitu, keparahan, deteksi kegagalan, dan frekuensi, yang menunjukan risiko yang mengarah pada tindakan perbaikan (Stamatis, 2015).

FMEA digunakan untuk mengetahui penyebab mesin mengalami kerusakan serta untuk mengetahui kegagalan yang paling berpengaruh pada mesin produksi (Asisco, Amar dan Perdana, 2012). Sedangkan LTA digunakan untuk menentukan klasifikasi kategori dari tiap kegagalan dari komponen prioritas, agar penanganannya sesuai dengan tiap kategori meliputi, kondisi, waktu dan temuan kegagalan (Asisco, Amar dan Perdana, 2012). Penggunaan FMEA dan LTA dilakukan untuk memberikan usulan penanganan yang tepat dalam pemeliharaan mesin yang dilakukan oleh perusahaan.

\section{METODOLOGI}

Penelitian menggunakan dua jenis data yaitu data primer dan data sekunder. Data primer yang berasal dari hasil observasi langsung di lapangan dan wawancara dengan pihak manajemen perusahaan. Data sekunder diperoleh dari informasi perusahaan, data standar industri dan referensi berdasarkan penelitian sebelumnya. Penelitian dilakukan dalam beberapa tahap, tahap pertama menghitung nilai efektivitas mesin menggunakan OEE. Perhitungan OEE dilakukan secara bertahap, dengan langkah perhitungan sebagai berikut (Stephens, 2010):

\section{Perhitungan Availability Ratio (AR)}

Nilai availability ratio (AR) dihitung menggunakan formula.

$$
A R=\frac{\text { loading time }- \text { downtime }}{\text { loading time }} \times 100 \%
$$

Perhitungan Performance Efficiency (PE) Nilai performance efficiency (PE) dihitung menggunakan rumus.

$$
P E=\frac{\text { Processed Amount } \times T C T}{\text { Operating Time }} \times 100 \%
$$

\section{Perhitungan Quality Rate (QR)}

Nilai quality rate (QR) dihitung menggunakan formula sebagai berikut:

$$
Q R=\frac{\left(\sum \text { processed }-\sum \text { defect }\right)}{\left(\sum \text { processed }\right)} \times 100 \%
$$

\section{Perhitungan OEE}

Nilai OEE dihitung menggunakan formula sebagai berikut:

$$
O E E=A R \times P E \times Q R
$$

Setelah nilai OEE diketahui, lalu dilakukan analisis terhadap faktor dengan nilai OEE rendah. Analisis dilaksanakan melalui wawancara dengan perusahaan yang terlibat pemeliharaan dan perawatan mesin. Wawancara dan analisis dilakukan berdasarkan metode FMEA dan LTA, untuk mengetahui titik kritis kerusakan mesin. 
Tabel 1 Data Total Produksi, Downtime dan Produk Cacat Periode April 2016 - Maret 2017

\begin{tabular}{lcccccc}
\hline \multicolumn{1}{c}{ Bulan } & \multicolumn{2}{c}{ Total Produksi (pcs) } & \multicolumn{2}{c}{ Total Down time (menit) } & \multicolumn{2}{c}{ Produk cacat (pcs) } \\
\cline { 2 - 7 } April 2016 & KR 2 & KR 3 & KR 2 & KR 3 & KR 2 & KR 3 \\
Mei 2016 & 1.330 .000 & 2.849 .500 & 17.145 & 2925 & 94.559 & 156.176 \\
Juni 2016 & 1.986 .000 & 2.831 .500 & 4990 & 3045 & 130.000 & 155.441 \\
Juli 2016 & 1.567 .000 & 627.500 & 770 & 10.045 & 67.059 & 30.735 \\
Agustus 2016 & 1.103 .500 & 999.300 & 640 & 11.515 & 53.088 & 169.961 \\
September 2016 & 926.500 & 1.910 .800 & 3655 & 6405 & 29.265 & 49.181 \\
Oktober 2016 & 1.297 .500 & 2.473 .500 & 2965 & 6265 & 139.559 & 248.632 \\
November 2016 & 967.500 & 3.011 .000 & 3670 & 3465 & 11.765 & 285.588 \\
Desember 2016 & 1.481 .200 & 2.284 .100 & 4000 & 10.055 & 321.786 & 253.000 \\
Januari 2017 & 774.500 & 3.291 .400 & 6370 & 650 & 78.529 & 404.265 \\
Februari 2017 & 1.554 .150 & 1.330 .000 & 2990 & 3015 & 223.550 & 248.088 \\
Maret 2017 & 1.508 .275 & 1.832 .500 & 2635 & 8400 & 213.053 & 198.529 \\
\hline & 1.596 .775 & 1.644 .300 & 4035 & 2525 & 177.206 & 177.206 \\
\hline
\end{tabular}

Tabel 1 menunjukan data yang dibutuhkan untuk perhitungan OEE. Mesin produksi yang diamati yaitu mesin molding dengan kode KR 2 dan KR 3, kedua mesin ini memiliki tingkat downtime paling tinggi dibanding mesin lain, dengan rata-rata waktu lebih dari 3.000 menit per bulannya. Total produksi menunjukan jumlah produk yang dibuat dalam satu periode. Total downtime menunjukan total waktu mesin tidak digunakan selama jam produksi (rusak, perbaikan, perawatan, set-up, dan lainnya). Produk cacat menunjukan jumlah produk yang tidak sesuai spesifikasi.

Tabel 2. Penyebab Nilai Efficiency Rendah

\begin{tabular}{|c|c|}
\hline Kategori & Six Big Losses \\
\hline \multirow{2}{*}{$\begin{array}{l}\text { Downtime } \\
\text { losses }\end{array}$} & Equipment failure \\
\hline & Setup and adjustment \\
\hline \multirow[t]{2}{*}{ Speed losses } & $\begin{array}{l}\text { Idling and minor } \\
\text { stoppages }\end{array}$ \\
\hline & Reduce speed \\
\hline Quality losses & $\begin{array}{l}\text { Process defect } \\
\text { Reduced yield }\end{array}$ \\
\hline
\end{tabular}

Rendahnya OEE disebabkan berbagai faktor. Kemudian dilakukan analisis untuk mengetahui penyebab utama yang dapat menyebabkan mesin tidak beroperasi normal dengan Six Big Losses (Rahmad, Pratikto dan Wahyudi, 2012). Six Big Losses adalah enam kerugian yang harus dihindari yang akan mengurangi efektivitas mesin Berdasarkan hasil wawancara dengan manajemen pabrik dan tinjauan literatur, diidentifikasi, bahwa kerugian dapat dibagi menjadi 3 kategori utama yaitu, downtime losses, speed losses, quality losses. Pengelompokan Six Big
Losses pada mesin perusahaan ditampilkan pada Tabel 2.

Downtime losses adalah waktu yang terbuang karena mesin tidak beroperasi. Downtime losses terdiri atas mesin rusak terjadi tiba-tiba (equipment failure) dan waktu yang hilang karena proses setup yang panjang (setup and adjustment). Kehilangan terjadi karena adanya waktu penyesuaian dan setup yang dibutuhkan untuk kegiatankegiatan penggantian produksi satu jenis produk ke jenis produk berikutnya.

Speed losses adalah keadaan dimana kecepatan mesin/proses produksi terganggu, hingga produksi tidak mencapai target. Speed losses terdiri dari 2 macam kerugian, yaitu idling and minor stoppage, kerugian yang dialami dikarenakan mesin mengalami kemacetan atau mengalami pemberhentian sejenak. Reduce speed losses, kerugian ini diakibatkan mesin mengalami penurunan kecepatan produksi. Menurunnya kecepatan mesin dapat disebabkan karena mesin yang dirancang tidak sesuai dengan penggunaan di pabrik; operator mesin tidak mengetahui kecepatan mesin seharusnya atau kecepatan diturunkan untuk pemeliharaan mesin.

Quality losses menggambarkan keadaan dimana produk yang dihasilkan tidak sesuai spesifikasi. Quality losses terdiri dari 2 (dua) jenis kerugian, yaitu kerugian karena produk hasil produksi memiliki kecacatan setelah keluar dari proses produksi (process defect) dan kerugian akibat produk yang dihasilkan tidak sesuai standar (reduce yield), karena perbedaan kualitas antara waktu mesin pertama kali dinyalakan dengan 
pada saat mesin tersebut sudah stabil beroperasi.

Tabel 3. Availability, Performance, Quality dan OEE Rate Mesin KR 2

\begin{tabular}{lcccc}
\hline \multicolumn{1}{c}{ Bulan } & $\begin{array}{c}\text { Availability Rate } \\
\text { KR2 }\end{array}$ & $\begin{array}{c}\text { Performance Rate } \\
\text { KR 2 }\end{array}$ & $\begin{array}{c}\text { Quality Rate } \\
\text { KR 2 }\end{array}$ & $\begin{array}{c}\text { OEE Rate } \\
\text { KR 2 }\end{array}$ \\
\hline April 2016 & $56,846 \%$ & $85,879 \%$ & $92,890 \%$ & $45,348 \%$ \\
Mei 2016 & $88,449 \%$ & $75,798 \%$ & $93,454 \%$ & $62,654 \%$ \\
Juni 2016 & $98,090 \%$ & $57,780 \%$ & $95,721 \%$ & $54,251 \%$ \\
Juli 2016 & $98,068 \%$ & $49,547 \%$ & $95,189 \%$ & $46,252 \%$ \\
Agustus 2016 & $91,539 \%$ & $45,556 \%$ & $96,841 \%$ & $40,385 \%$ \\
September 2016 & $93,137 \%$ & $53,747 \%$ & $89,244 \%$ & $44,674 \%$ \\
Oktober 2016 & $91,779 \%$ & $45,918 \%$ & $88,448 \%$ & $37,274 \%$ \\
November 2016 & $90,741 \%$ & $73,472 \%$ & $78,275 \%$ & $52,186 \%$ \\
Desember 2016 & $85,730 \%$ & $39,351 \%$ & $89,861 \%$ & $30,315 \%$ \\
Januari 2017 & $92,840 \%$ & $80,730 \%$ & $85,616 \%$ & $64,169 \%$ \\
Februari 2017 & $93,223 \%$ & $63,576 \%$ & $85,874 \%$ & $50,895 \%$ \\
Maret 2017 & $90,961 \%$ & $79,195 \%$ & $88,902 \%$ & $64,042 \%$ \\
\multicolumn{1}{c}{ Rata - Rata } & $\mathbf{8 9 , 2 8 4 \%}$ & $\mathbf{6 2 , 5 4 6 \%}$ & $\mathbf{9 0 , 0 2 6 \%}$ & $\mathbf{4 9 , 3 7 0 \%}$ \\
\hline
\end{tabular}

Tabel 4. Availability, Performance, Quality dan OEE Rate Mesin KR 3

\begin{tabular}{lcccc}
\hline \multicolumn{1}{c}{ Bulan } & $\begin{array}{c}\text { Avaibility Rate } \\
\text { KR3 }\end{array}$ & $\begin{array}{c}\text { Performance Rate } \\
\text { KR3 }\end{array}$ & $\begin{array}{c}\text { Quality Rate } \\
\text { KR3 }\end{array}$ & $\begin{array}{c}\text { OEE Rate } \\
\text { KR3 }\end{array}$ \\
\hline April 2016 & $93,010 \%$ & $97,102 \%$ & $94,519 \%$ & $85,365 \%$ \\
Mei 2016 & $92,951 \%$ & $91,815 \%$ & $94,510 \%$ & $80,659 \%$ \\
Juni 2016 & $75,087 \%$ & $35,696 \%$ & $95,102 \%$ & $25,490 \%$ \\
Juli 2016 & $65,232 \%$ & $74,680 \%$ & $82,992 \%$ & $40,430 \%$ \\
Agustus 2016 & $85,174 \%$ & $86,552 \%$ & $97,426 \%$ & $71,822 \%$ \\
September 2016 & $85,498 \%$ & $87,199 \%$ & $89,948 \%$ & $67,059 \%$ \\
Oktober 2016 & $92,238 \%$ & $95,217 \%$ & $90,515 \%$ & $79,496 \%$ \\
November 2016 & $76,725 \%$ & $89,730 \%$ & $88,923 \%$ & $61,219 \%$ \\
Desember 2016 & $98,532 \%$ & $98,228 \%$ & $87,718 \%$ & $84,898 \%$ \\
Januari 2017 & $92,780 \%$ & $57,212 \%$ & $81,347 \%$ & $43,180 \%$ \\
Februari 2017 & $77,564 \%$ & $82,165 \%$ & $89,166 \%$ & $56,826 \%$ \\
Maret 2017 & $94,344 \%$ & $52,871 \%$ & $89,223 \%$ & $44,505 \%$ \\
\multicolumn{1}{c}{ Rata - Rata } & $\mathbf{8 5 . 7 6 \%}$ & $\mathbf{7 9 . 0 4 \%}$ & $\mathbf{9 0 . 1 2 \%}$ & $\mathbf{6 1 . 7 5 \%}$ \\
\hline
\end{tabular}

\section{HASIL DAN PEMBAHASAN}

Tabel 3 dan 4 memperlihatkan hasil perhitungan OEE untuk mesin KR 2 dan KR 3, yang dihitung berdasarkan nilai availability rate, performance rate dan quality rate (persamaan 1,2 , dan 3 ). Nilai OEE dihitung dengan mengalikan nilai dari ketiga faktor tersebut (persamaan 4). Nilai OEE setiap mesin berfluktuasi menandakan kinerja mesin produksi yang dimiliki perusahaan tidak stabil.

Rendahnya nilai OEE pada mesin KR 2 dan KR 3, sangat dipengaruhi oleh nilai performance efficiency rate yang rendah. Nilai performance efficiency rate digunakan untuk melihat indikasi losses dari speed losses. Speed losses salah satunya disebabkan oleh reduce speed. Reduce speed merupakan suatu keadaan dimana mesin dioperasikan dengan kecepatan yang tidak sesuai dengan kecepatan ideal.

Berdasarkan wawancara, rendahnya nilai performance disebabkan perusahaan sengaja menurunkan kecepatan mesin untuk menjaga suhu mesin agar kualitas produk tidak turun. Selain itu perubahan kecepatan dilakukan untuk menyesuaikan tingkat permintaan konsumen. Pada Tabel 4 terlihat nilai availability mesin mencapai nilai terendah pada bulan Juli 2016 yang mencapai $65 \%$, hal tersebut terjadi karena kerusakan mesin yang membutuhkan pergantian onderdil. Ketidaksiapan dalam menyediakan onderdil, menyebabkan mesin dapat diperbaiki dalam waktu yang lama. Pada Tabel 3, performance rate mengalami 
pergerakan fluktuatif. Nilai performance rate terendah pada mesin KR2, disebabkan rendahnya hasil produksi dibanding dengan waktu yang tersedia. Selain itu, perbedaan cycle time memberi pengaruh yang cukup besar.

Tabel 4 , menunjukan rata-rata quality rate cukup baik. Quality rate dipengaruhi oleh jumlah produk cacat yang dihasilkan. Nilai OEE rendah disebabkan rendahnya performance efficiency rate. Hal tersebut disebabkan mesin mengalami perubahan kecepatan yang tidak sesuai dengan kemampuan mesin, dan karena operator mengubah kecepatan mesin, yang sengaja diturunkan oleh operator untuk menjaga kualitas produk. Menurut operator, jika kecepatan tidak diturunkan, mesin akan panas dan dapat menyebabkan hasil cetakan menempel pada mesin dan produk cacat.

\section{Failure Mode and Effect Analysis (FMEA)}

Berdasarkan pengamatan, rendahnya nilai performance rate pada kedua mesin disebabkan losses idling, minor stoppages dan reduce speed. Kemudian, identifikasi sebab kegagalan tertinggi pada idling and minor stoppages dan reduce speed dilakukan menggunakan pendekatan FMEA dengan menganalisis failure mode dan failure effect. Data FMEA diperoleh dari observasi, dan wawancara dengan berbagai pihak terlibat, yaitu supervisor produksi, perawatan, dan operator. Deskripsi tiap failure mode dan failure effect ditampilkan pada Tabel 5.

Effect (dampak) dari kegagalan yang dicantumkan pada Tabel 5 merupakan efek langsung yang ditimbulkan dari penyebab kegagalan. Uraian mengenai penyebab dan efek dari setiap kegagalan adalah sebagai berikut:

1. Produk tidak sesuai standar

Penyebab terjadinya kegagalan produk antara lain disebabkan oleh, parisson tidak center dan chiller tersumbat. Parison merupakan bagian mesin yang berfungsi untuk mengeluarkan adonan plastik panas yang kemudian dibentuk pada mould untuk menjadi botol plastik. Kegagalan ini menyebabkan timbulnya noda putih (flashing) pada produk dan mould menjadi panas, yang membuat proses pencetakan tidak sempurna.

2. Potongan produk tidak sesuai spesifikasi Penyebab kegagalan ini, adalah cooling kurang dingin, pisau tumpul, neck terlalu panas, dan setting mould tidak sesuai. Hal ini menyebabkan ada bagian plastik yang menempel, adanya gutter, over cutting, produk macet dan produk terjepit. Hal ini mengharuskan mesin berhenti beroperasi untuk perbaikan.

3. Produk tidak jadi

Produk tidak jadi disebabkan hot cutting putus, blowpin dan origa tersumbat. Hal tersebut berakibat mesin tidak memotong cetakan dengan tepat, tidak meniup angin dan dapat menyebabkan mesin berhenti tiba-tiba, kegagalan ini membutuhkan perbaikan yang lama.

4. Mesin mati/tidak berfungsi

Kompresor rusak dan hidrolik overload merupakan mengakibatkan mesin tidak beroperasi. Kegagalan ini membutuhkan waktu perbaikan mesin yang sangat lama yang merugikan perusahaan.

Setelah mengidentifikasi kegagalan, penyebab kegagalan dan akibat kegagalan mesin, selanjutnya tingkat kegagalan tertinggi dilakukan dengan menghitung nilai risk prioriy number (RPN). RPN menggambarkan keterkaitan antara variabel dalam analisis risiko, yaitu severity (tingkat keparahan), occurrence (frekuensi kejadian) dan detection (kemudahan pendeteksian kegagalan) yang ditujukan untuk perbaikan sistem pemeliharaan mesin produksi. Anallisis RPN dilakukan melalui tahapan wawancara dengan pihak manajemen dan operator produksi melalui diskusi dan kuesioner yang telah disiapkan. 


\section{Tabel 5. Analisis Failure Mode dan Failure Effect}

\begin{tabular}{|c|c|c|c|}
\hline No & Failure & Failure Mode & Failure Effect \\
\hline \multirow[t]{2}{*}{1} & \multirow{2}{*}{$\begin{array}{l}\text { Produk H1 tidak sesuai } \\
\text { dengan standar }\end{array}$} & Parisson tidak center & Terdapat flashing pada produk \\
\hline & & Chiller tersumbat & $\begin{array}{l}\text { Mould menjadi lebih panas dari } \\
\text { seharunya }\end{array}$ \\
\hline \multirow[t]{4}{*}{2} & \multirow{4}{*}{$\begin{array}{l}\text { Potongan produk tidak } \\
\text { sesuai dengan spesifikasi }\end{array}$} & Cooling kurang dingin & Terdapat runner yang menempel \\
\hline & & Pisau tumpul & Adanya gutter dan over cutting \\
\hline & & Neck lengket / terlalu panas & Produk macet pada proses cutting \\
\hline & & Setting mould tidak benar & Produk terjepit \\
\hline \multirow[t]{3}{*}{3} & \multirow[t]{3}{*}{ Produk tidak jadi } & Hot cutting putus & Tidak dapat memotong parrison \\
\hline & & Blowpin mampet & Tidak dapat memblowing \\
\hline & & Origa mampet & Tidak dapat meniupkan angin \\
\hline \multirow[t]{2}{*}{4} & \multirow{2}{*}{$\begin{array}{l}\text { Mesin mati/tidak } \\
\text { berfungsi }\end{array}$} & Kompresor rusak & Tidak dapat menghasikan produk \\
\hline & & Hidrolik overload & Tidak dapat menghasilkan produk \\
\hline
\end{tabular}

Analisis RPN dilakukan pada komponen dengan nilai RPN yang dikategorikan sebagai risiko kritis, nilai RPN yang berada diatas nilai kritis ditetapkan sebagai prioritas tindakan perbaikan yang harus diambil, untuk mengatasinya rendahnya nilai OEE. Apabila perusahaan sudah memiliki standar nilai kritis maka standar tersebut digunakan sebagai acuan, namun jika belum menetapkan nilai kritis, maka nilai kritis dapat di tentukan berdasarkan referensi dari mesin produksi yang memiliki karakteristik sama. Perhitungan nilai kritis dilakukan dengan menghitung total nilai RPN dengan jumlah risiko yang teridentifikasi (Yumaida, 2011). Berdasarkan hasil wawancara penilaian RPN pada Tabel 6, dapat dihitung nilai RPN akhir sebagai berikut:

Nilai Kritis $=\frac{\text { Total RPN }}{\text { Jumlah Risiko }}=\frac{374}{11}=34$

Dari analisis FMEA yang dilakukan pada Tabel 6, diperoleh 11 penyebab kegagalan kritis. Setiap kegalan kemudian dinilai dari tingkat keparahan (S), frekuensi (F), kemudahan pendektesian kegagalan (D). Diperoleh nilai kritis RPN, sebesar 34. Dari 11 kegagalan yang teridentifikasi, diketahui 5 penyebab kegagalan yang memiliki nilai RPN lebih kecil dari 34, yaitu cooling kurang dingin, neck-molding lengket, blowing-pin macet, origa tersumbat, komproser rusak dan hidrolik mengalami overload.

Berdasarkan hasil analisis, penyebab kegagalan dengan RPN diatas nilai kritis yang dizinkan adalah sebagai berikut:
1. Material

Penyebab kegagalan adalah material terlalu lembab, temperatur tempat material dimasak terlalu tinggi.

2. Mesin

Penyebab kegagalan antara lain bentuk kontruksi mould kurang baik, sehingga mould mudah panas dan kotor; parisson tidak center dan arison tersumbat..

3. Manusia

Operator kurang mendapatkan mematuhi standar kerja ketika melakukan penstelan ulang dan pemasangan komponen.

4. Metode

Perusahaan saat ini belum menjalankan preventive maintenance, perbaikan hanya dilakukan saat kegagalan terjadi.

\section{Logic Tree Analysis (LTA)}

Selanjutnya dilakukan analisis LTA, (Tabel 6) untuk mengklasifikasi penyebab kegagalan menjadi beberapa kategori untuk ditentukan tingkat prioritas penanganan tiap kategorinya. Kategori failure mode dalam LTA, dapat digolongkan dalam beberapa kategori yaitu, safety and enviromental consequances, operational consequances dan hidden failure (Deshpande dan Modak, 2002). Kategori LTA dalam penelitian ini adalah sebagai berikut:

1. Kategori A, jika failure mode mempunyai konsekuensi safety terhadap personel maupun lingkungan.

2. Kategori B, jika failure mode mempunyai konsekuensi terhadap operasional pabrik yang dapat menyebabkan kerugian ekonomi secara signifikan. 
3. Kategori C, jika failure mode tidak berdampak pada operasional pabrik dan menyebabkan kerugian ekonomi yang relatif kecil untuk perbaikan.

4. Kategori D, jika failure mode tergolong sebagai hidden failure, digolongkan lagi dampak yang mungkin dihasilkan dari hidden failure ke dalam kategori D/A, kategori D/B dan kategori D/C.

Berdasarkan Tabel 6 tidak ditemui kegagalan yang tergolong dalam Kategori A. Artinya kegagalan tidak memberikan konsekuensi pada keselamatan, kesehatan pekerja dan lingkungan. Sebagian besar kegagalan digolongkan dalam kategori $\mathrm{B}$, artinya kegagalan menyebabkan sistem kerja terhenti. Kegagalan yang termasuk dalam kategori ini adalah setting second mold tidak benar, yang menyebakan produk cacat. Penanganan hal ini dilakukan dengan penyetelan ulang mesin, yang menyebabkan mesin berhenti beroperasi Origa tersumbat dan neck lengket, termasuk dalam kategori D/B, artinya kerusakan ini tidak mudah terdeteksi langsung (hidden failure), namun ketika kerusakan terjadi, menyebabkan kerugian ekonomi. Cooling kurang dingin masuk kategori kegagalan yang tidak mudah terdeteksi, kerusakan .baru diketahui ketika botol plastik memiliki neck tidak rapih. Kategorisasi penyebab kerusakan dilakukan untuk menentukan prioritas penangan untuk setiap kegagalan yang terjadi. Penanganan diprioritaskan untuk kegagalan yang masuk dalam kategori LTA B dan hidden failure mengarah pada kategori B.

Tabel 6. Nilai RPN Kegagalan

\begin{tabular}{|c|c|c|c|c|c|c|c|c|c|}
\hline No & Failure & $\begin{array}{l}\text { Failure } \\
\text { Mode }\end{array}$ & Failure Effect & $\mathbf{S}$ & $\mathbf{O}$ & D & $\mathbf{R P N}$ & $\begin{array}{c}\text { Kategori } \\
\text { LTA }\end{array}$ & $\begin{array}{c}\text { Usulan } \\
\text { Perbaikan }\end{array}$ \\
\hline \multirow[t]{2}{*}{1} & \multirow[t]{2}{*}{$\begin{array}{l}\text { Produk H1 } \\
\text { tidak sesuai } \\
\text { dengan } \\
\text { standar }\end{array}$} & $\begin{array}{l}\text { Parisson } \\
\text { tidak center }\end{array}$ & $\begin{array}{l}\text { Terdapat } \\
\text { flashing pada } \\
\text { produk }\end{array}$ & 4 & 4 & 4 & 64 & $\mathrm{C}$ & $\begin{array}{l}\text { Lakukan } \\
\text { kalibrasi mesin } \\
\text { secara rutin } \\
\text { tiap, } \\
\text { memastikan } \\
\text { parison center }\end{array}$ \\
\hline & & $\begin{array}{l}\text { Chiller } \\
\text { tersumbat }\end{array}$ & $\begin{array}{l}\text { Mould } \\
\text { menjadi panas }\end{array}$ & 4 & 4 & 3 & 48 & B & $\begin{array}{l}\text { Melakukan } \\
\text { pengecekan } \\
\text { dan menjaga } \\
\text { stabilitas suhu }\end{array}$ \\
\hline \multirow[t]{4}{*}{2} & \multirow[t]{4}{*}{$\begin{array}{l}\text { Potongan } \\
\text { produk } \\
\text { tidak sesuai } \\
\text { dengan } \\
\text { spesifikasi }\end{array}$} & $\begin{array}{l}\text { Cooling } \\
\text { kurang } \\
\text { dingin }\end{array}$ & $\begin{array}{l}\text { Terdapat } \\
\text { runner yang } \\
\text { menempel }\end{array}$ & 5 & 4 & 2 & 32 & $\mathrm{D} / \mathrm{C}$ & $\begin{array}{l}\text { Memeriksa } \\
\text { suhu dan } \\
\text { kondisi cooling } \\
\text { dalam } \\
\text { temperatur } \\
\text { yang tepat }\end{array}$ \\
\hline & & $\begin{array}{l}\text { Pisau } \\
\text { tumpul }\end{array}$ & $\begin{array}{l}\text { Adanya gutter } \\
\text { dan over } \\
\text { cutting }\end{array}$ & 8 & 3 & 2 & 48 & $\mathrm{C}$ & $\begin{array}{l}\text { Melakukan } \\
\text { penjadwalan } \\
\text { pergantian } \\
\text { pisau secara } \\
\text { teratur. }\end{array}$ \\
\hline & & $\begin{array}{l}\text { Neck } \\
\text { lengket / } \\
\text { terlalu } \\
\text { panas }\end{array}$ & $\begin{array}{l}\text { Produk macet } \\
\text { pada proses } \\
\text { cutting }\end{array}$ & 3 & 3 & 2 & 18 & $\mathrm{D} / \mathrm{B}$ & $\begin{array}{l}\text { Menjaga } \\
\text { temperature } \\
\text { pada kondisi } \\
\text { optimal. }\end{array}$ \\
\hline & & $\begin{array}{l}\text { Setting } \\
\text { second } \\
\text { mould tidak } \\
\text { benar }\end{array}$ & $\begin{array}{l}\text { Produk } \\
\text { terjepit }\end{array}$ & 3 & 4 & 3 & 36 & B & $\begin{array}{l}\text { Lakukan } \\
\text { kalibrasi } \\
\text { pemasangan } \\
\text { mould secara } \\
\text { rutin tiap } \\
\text { setting ulang. }\end{array}$ \\
\hline
\end{tabular}




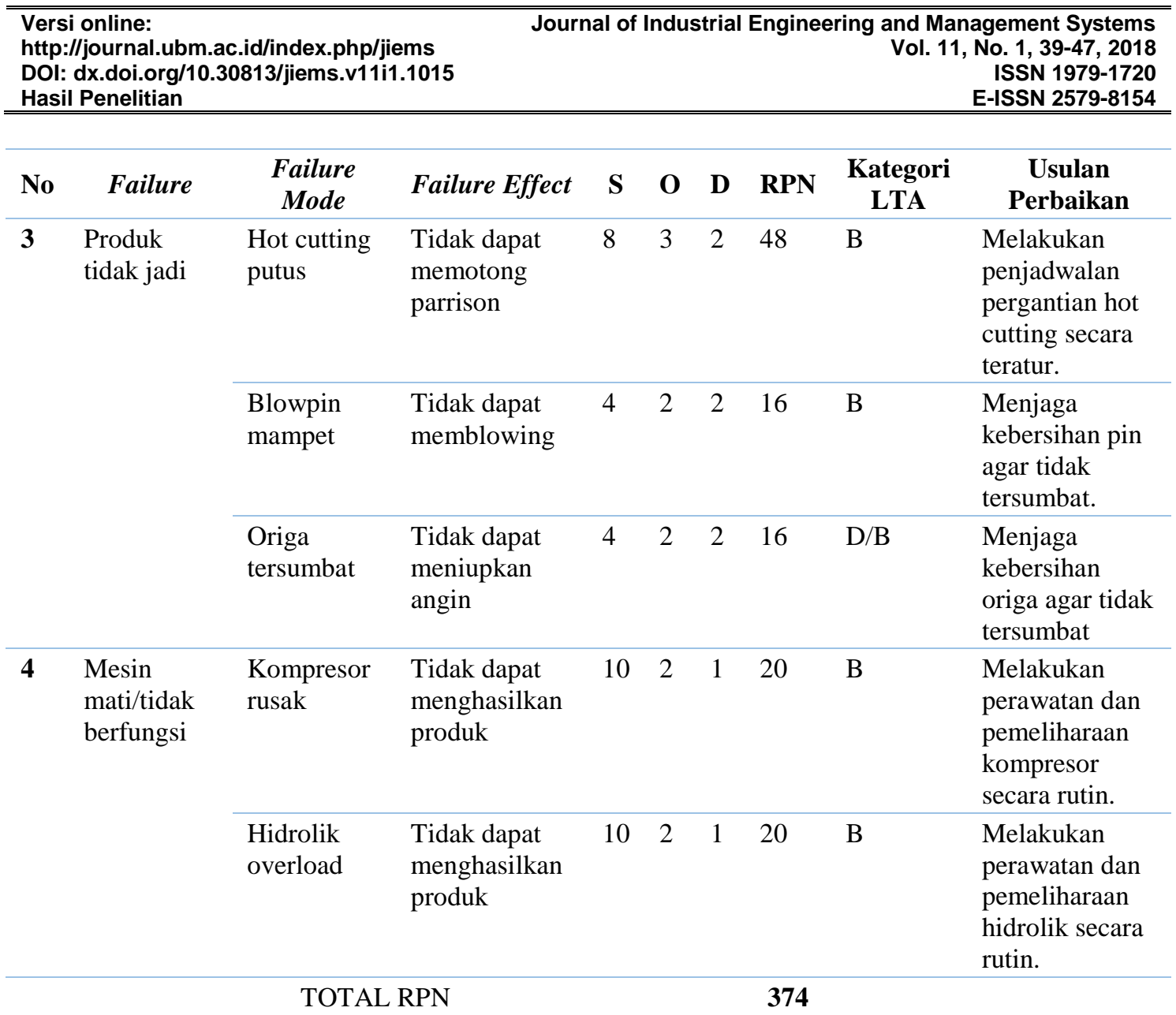

\section{KESIMPULAN}

Berdasarkan pembahasan, diketahui bahwa Nilai OEE yang dicapai oleh mesin belum dapat diterima karena nilainya masih berada dibawah kondisi ideal efektivitas mesin yaitu 85\% (Chand dan Shirvani, 2000). Hasil FMEA dan nilai RPN kritis menunjukan kegagalan yang menjadi prioritas perbaikan adalah parisson tidak center, chiller tersumbat, hot cutting putus, pisau tumpul, cooling kurang dingin, neck cepat panas, blowpin dan origa tersumbat. Berdasarkan kategori kegagalan, pihak manajemen sebaiknya fokus pada kategori B/D yaitu origa tersumbat dan cooling kurang dingin.

Nilai OEE menghitung efektivitas mesin produksi dengan mengalikan nilai availability ratio, performance effeciency, dan quality rate, secara merata, tanpa memberikan bobot untuk tiap faktor, sehingga jika salah-satu komponen buruk, dapat tertutupi dengan komponen lainnya yang bernilai baik. Hal ini menimbulkan risiko tersembunyi yang tidak terdeteksi oleh sistem. Penelitian selanjutnya dapat melihat penyebab kritis kerusakan secara lebih rinci.

\section{DAFTAR PUSTAKA}

Ansori, N. dan Mustajib, M. I. (2013) Sistem Perawatan Terpadu. 1 ed. Yogyakarta: Graha Ilmu. Asisco, H., Amar, K. dan Perdana, Y. R. (2012) "Usulan Perencanaan Perawatan Mesin dengan Metode Reliability Centered Maintenance (RCM) di PT. Perkebunan Nusantara VII (Persero) Unit Usaha Sungai Niru Kab. Muara Enim," Kaunia, 8(2), hal. 78-98.

Chand, G. dan Shirvani, B. (2000) "Implementation of TPM in Cellular Manufacture," Journal of Materials Processing Technology, 103(1), hal. 149-154. doi: 10.1016/S09240136(00)00407-6.

Deshpande, V. S. dan Modak, J. P. (2002) "Application of RCM to a Medium Scale Industry," Reliability Engineering and System Safety, 77(1), hal. 31-43. doi: 10.1016/S09518320(02)00011-X. 
Muchiri, P. dan Pintelon, L. (2008) "Performance Measurement Using Overall Equipment Effectiveness (OEE): Literature Review and Practical Application Discussion," International Journal of Production Research, 46(13), hal. 3517-3535. doi: 10.1080/00207540601142645.

Rahmad, Pratikto dan Wahyudi, S. (2012) "Penerapan Overall Equipment Effectiveness (OEE) dalam Implementasi Total Productive Maintenance (TPM) (Studi Kasus di Pabrik Gula PT. 'Y'),' Jurnal Rekayasa Mesin, 3(3), hal. 431-437.

Stamatis, D. H. (2015) The ASQ Pocket Guide to Failure Mode and Effect Analysis (FMEA). Milwaukee: American for Quality, Quality Press.

Stephens, M. P. (2010) Productivity and Reliability-based Maintenance Management. Purdue University Press.

Yumaida (2011) Analisis Risiko Kegagalan Pemeliharaan pada Pabrik Pengolahan Pupuk NPK Granular (Studi Kasus: PT. Pupuk Kujang Cikampek). Universitas Indonesia. 